\title{
A FRAMEWORK FOR CAPACITY BUILDING IN MAPPING COASTAL RESOURCES USING REMOTE SENSING IN THE PHILIPPINES
}

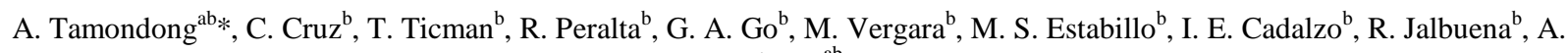 \\ Blanco $^{\text {ab }}$ \\ ${ }^{a}$ Environmental Systems Applications of Geomatics Engineering (EnviSAGE) Research Laboratory, Department of Geodetic \\ Engineering, University of the Philippines, Diliman, Quezon City 1101, Philippines - ayin_t@yahoo.com \\ ${ }^{\mathrm{b}}$ Phil-LiDAR2, Training Center for Applied Geodesy and Photogrammetry, Department of Geodetic Engineering, University of the \\ Philippines, Diliman, Quezon City 1101, Philippines
}

\author{
Commission VI, WG VI/6
}

KEY WORDS: Coastal Resources Mapping, LiDAR, Remote Sensing, Capacity Building, Philippines

\begin{abstract}
:
Remote sensing has been an effective technology in mapping natural resources by reducing the costs and field data gathering time and bringing in timely information. With the launch of several earth observation satellites, an increase in the availability of satellite imageries provides an immense selection of data for the users. The Philippines has recently embarked in a program which will enable the gathering of LiDAR data in the whole country. The capacity of the Philippines to take advantage of these advancements and opportunities is lacking. There is a need to transfer the knowledge of remote sensing technology to other institutions to better utilize the available data. Being an archipelagic country with approximately 36,000 kilometers of coastline, and most of its people depending on its coastal resources, remote sensing is an optimal choice in mapping such resources. A project involving fifteen (15) state universities and colleges and higher education institutions all over the country headed by the University of the Philippines Training Center for Applied Geodesy and Photogrammetry and funded by the Department of Science and Technology was formed to carry out the task of capacity building in mapping the country's coastal resources using LiDAR and other remotely sensed datasets. This paper discusses the accomplishments and the future activities of the project.
\end{abstract}

\section{INTRODUCTION}

\subsection{Background}

The Philippines is an archipelagic country with approximately 7,100 islands and 36,000 kilometers of coastline. Many of its people depend on coastal resources for daily necessities such as food. Due to population growth and industrialization, the coastal environment and its resources are being threatened. Integrated management is widely recognized as the basis for sustainable use and to achieve this, an evaluation and mapping of the resources is needed. Inventory of these resources provide important baseline data for resource management which can help in decision making in planning and development. Using the traditional method of field sampling to map these resources will be too difficult, time consuming and expensive. With the latest technologies such as remote sensing, mapping the coastal resources of the Philippines is not too farfetched. Unfortunately, the expertise to use such technology is concentrated in a few areas in the country.

The University of the Philippines Training Center for Applied Geodesy and Photogrammetry (UP TCAGP) funded by the Department of Science and Technology (DOST) initially embarked in the Disaster Risk and Exposure Assessment for Mitigation (DREAM) Program to use LiDAR data to create highly accurate Digital Surface Model (DSM) and Digital Terrain Model (DTM) of the country for flood modelling. This program has four (4) projects under it: Data Acquisition, Data Processing, Data Validation and Flood Modelling. For 2 years the program captured LiDAR data using two (2) topographic and one (1) bathymetric LiDAR across flood plains and major river basins all over the country. Because of the success of the
DREAM Program, the DOST realized the capability of LiDAR data, thus, the Phil-LiDAR Programs were born.

The Phil-LiDAR is composed of two (2) programs. Phil-LiDAR 1 is the extension of the DREAM program while the PhilLiDAR 2 is the Nationwide Detailed Resources Assessment Using LiDAR. Under the Phil-LiDAR 2 program are 5 projects and one of them is the Aquatic Resources Extraction from LiDAR Surveys (CoastMap). The program headed by the UP Diliman (UPD) Training Center for Applied Geodesy and Photogrammetry (TCAGP) partnered with fourteen (14) state universities (SUCs) and higher education institutions (HEIs) all over the country to achieve its objectives. The program is designed to be implemented for three (3) years starting from the $3^{\text {rd }}$ quarter of 2014 to the $2^{\text {nd }}$ quarter of 2017.

\subsection{Objectives of the Project}

The main objective of Phil-LiDAR 2 Project 2 - Aquatic Resources Extraction from LiDAR Surveys (CoastMap) is to map the high valued coastal resources such as benthic habitats, mangroves and aquaculture of the Philippines. To be able to do that, different workflows were developed, tested, and assessed for extraction of such resources using LiDAR and other remotely sensed datasets for pilot sites which will then be applied to other images covering the whole country. Another objective of the project is capacity building. The CoastMap team was tasked to conduct trainings on basic remote sensing and GIS to the fifteen (14) partner SUCs and HEIs, cascade the workflows the team developed and monitor their progress. Each partner was tasked to map the coastal areas near their campuses (Figure 1). The 14 partners are Mariano Marcos State University (MMSU), Isabela State University (ISU), Central 
Luzon State University (CLSU), Mapua Institute of Technology (MIT), University of the Philippines Los Banos (UPLB), Ateneo de Naga University (ADNU), University of the Philippines Cebu (UP Cebu), University of San Carlos (USC), Visayas State University (VSU), Ateneo de Zamboanga University (ADZU), Central Mindanao University (CMU), Mindanao State University - Illigan Institute of Technology (MSU-IIT), UP Mindanao (UP Min) and Caraga State University (CSU).

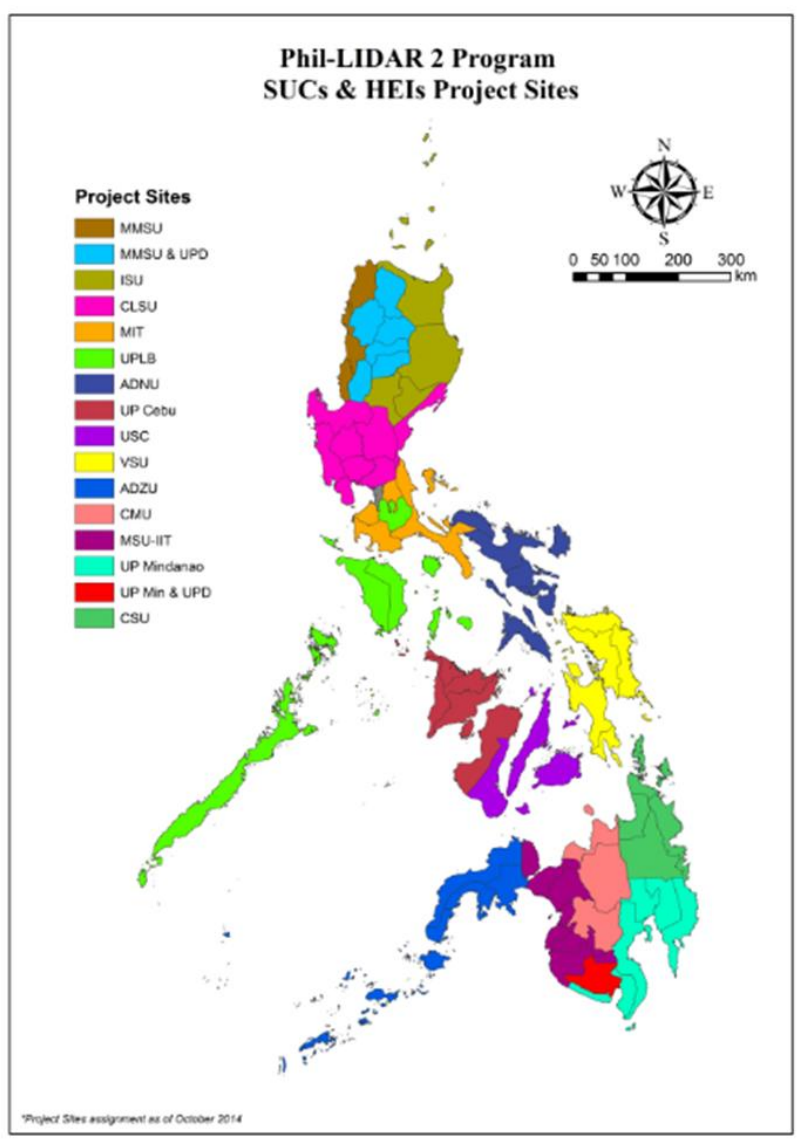

Figure 1. Project Sites of Phil-LiDAR 2 SUCs and HEIs

\subsection{Project Team}

The lead team from UP TCAGP is composed of one (1) Project Leader (PL), three (3) Project Support Staff (PSS), eight (8) Science Research Specialists (SRS) and one (1) Project Development Officer (PDO). The 3 PSS have different tasks, one is for technical, one for administrative and one from a government agency which is the Bureau of Fisheries and Aquatic Resources (BFAR). The PDO is dedicated to do all the administrative works of the project while all the SRS are tasked to do the research, mentoring and monitoring of the SUCs and HEIs.

\subsection{Project Workflow}

The project started with hiring of manpower and procurement of the necessary equipment. After being hired, the researchers then continued with a comprehensive review of related literatures while the project leader headed the coordination meetings with concerned agencies and offices such as the National Mapping and Resource Information Authority (NAMRIA), Bureau of Biodiversity and Management (BMB) and BFAR and also with the partner SUCs and HEIs. Secondary data were gathered from other institutions such as the Department of Natural Resources (DENR) and University of the Philippines Marine Science Institute (UP MSI). Algorithms and workflows to extract coastal resources from LiDAR and other remotely sensed data were then developed. These workflows were cascaded to the SUCs and HEIs. The researchers visit each partner university for the mentoring sessions. The partner universities were also invited for group trainings at the UP TCAGP. Each university conduct their own internal trainings to capacitate their staff with the knowledge they learned from the trainings.

The partner SUC and HEIs process their own set of data and do fieldwork in their study areas. All their output is sent to UP TCAGP for quality assessment and checking.

\section{SUMMARY OF ACTIVITIES}

\subsection{Development of Workflows and Algorithms}

During the project's first 6 months, it was able to develop the following methods for its objectives: object-based image analysis for benthic habitat mapping using LiDAR derivatives, object-based image analysis for extracting aquaculture classes using LiDAR datasets, object-based image analysis for extracting mangroves using LiDAR and orthophoto datasets (Figure 3), extraction of coastal aquaculture features (fish ponds, fish pens, fish cages extraction) from high resolution WorldView-2 satellite images using object-oriented approach, object-based image analysis for benthic habitat mapping using high resolution WorldView-2 satellite images and mangrove mapping from Landsat images.

The remainder of the project's first year was dedicated for refinement and updating of workflows and also for developing new workflow such as object-based image analysis of benthic habitat classification using fusion of high resolution images (WorldView-2) and LiDAR point cloud data, mangrove mapping in coastal environment using multispectral imagery and LiDAR data, mapping of coastal fish pens and fish cages though object-based image analysis of Lidar data and its derivatives, integration of LiDAR and WorldView-2 image for the extraction of coastal aquaculture features (fish ponds, fish pens, fish cages extraction) using object-oriented approach and pixel-based image analysis for benthic habitat mapping using Landsat 8 satellite imagery.

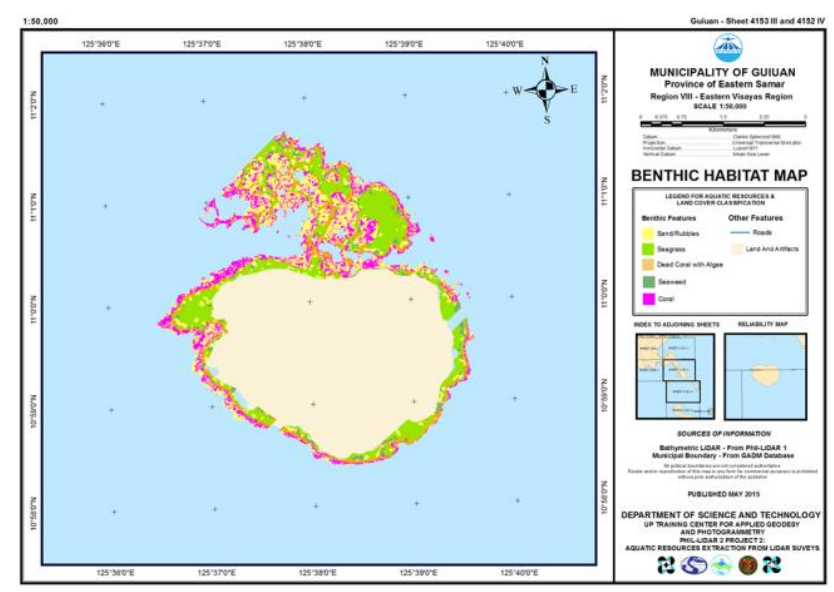

Figure 2. Sample Benthic Habitat Map of Manicani Island, Guiuan, Eastern Samar from LiDAR data 


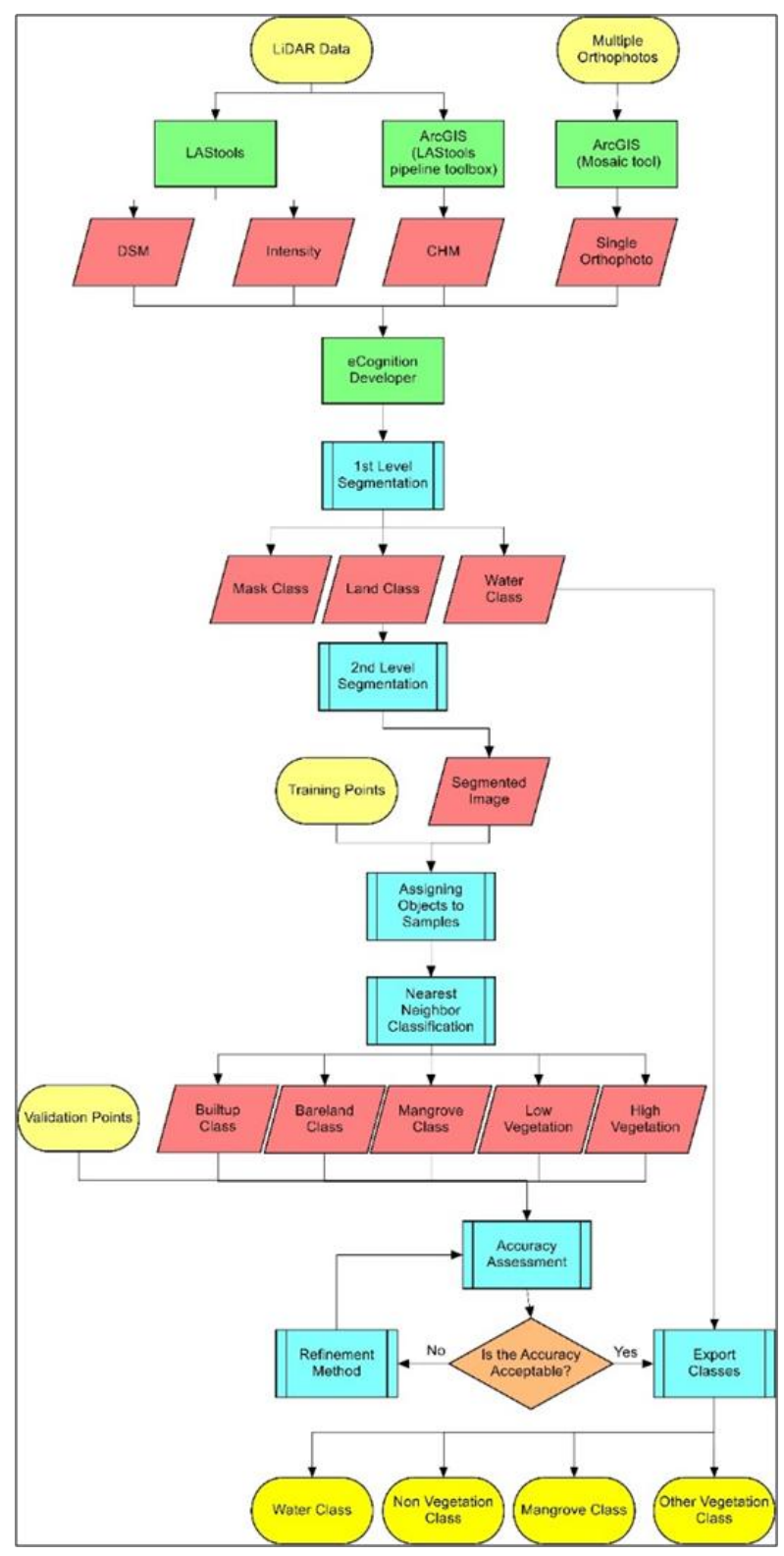

Figure 3. Sample workflow for extracting mangroves using LiDAR and orthophoto datasets

\subsection{Field Surveys}

In the extraction of coastal resources from remotely sensed data, field surveys to collect training and validation points are done in order to calibrate the classification processes and validate the resulting maps. The ground data collected aids in the assessment of the quality of the extracted information.

The UPD CoastMap team employs various methods of field data collection in order to produce detailed maps of the coastal resources. Included in these methods are ocular inspections, GPS location sampling, and underwater video tows.

Some field surveys are jointly conducted by the UPD team and the partner university. This is carried out to train other researchers on data gathering and for validation purposes as well.

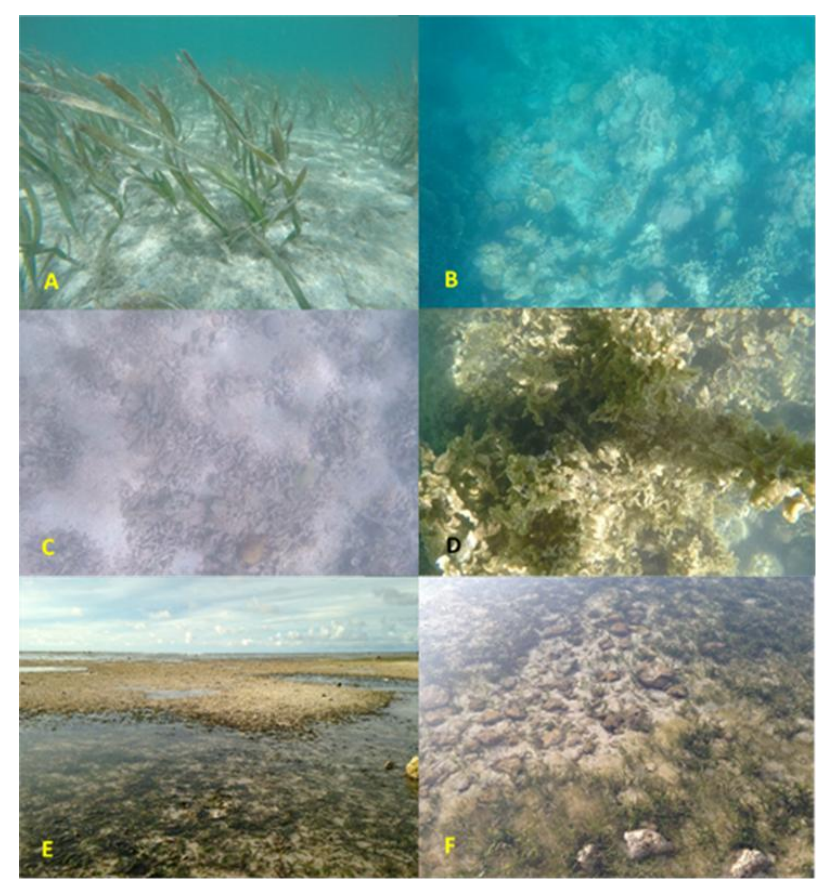

Figure 4. Samples of different benthic features observed in the Easter Samar during a field survey. A. Extensive seagrass (Enhalus acoroides); B. Live corals found in reef edges; C. Sand and coral rubbles; D. Seaweed (Sargassum sp.); E. Exposed intertidal area showing the seagrasse

\subsection{Training and Mentoring Sessions}

During the $1^{\text {st }}$ year of implementation of the project, the partner SUCs and HEIs were taught the basics of remote sensing and the initial workflows developed by the project which includes LiDAR, WorldView-2 and Landsat preprocessing and extraction of coastal resources using object oriented image analysis and pixel based classification. Two (2) or more researchers from the UPD CoastMap visited each university to lecture and mentor researchers from the partner institutions.

\begin{tabular}{|c|c|}
\hline Mariano Marcos State University & $\begin{array}{c}\text { November 11-14, } \\
2014 \\
\end{array}$ \\
\hline Isabela State University & December 10-12, 2014 \\
\hline Central Luzon State University & November 5-7, 2014 \\
\hline Mapua Institute of Technology & \multirow{2}{*}{ October 13-15, 2014} \\
\hline UP Los Baños & \\
\hline Ateneo de Naga University & October 15.17, 2014 \\
\hline UP Cebu & \multirow{3}{*}{$\begin{array}{c}\text { September } 25-26 \text {, } \\
2014\end{array}$} \\
\hline University of San Carlos & \\
\hline Visayas State University & \\
\hline Ateneo de Zamboanga University & October 20-23, 2014 \\
\hline UP Mindanao & $\begin{array}{c}\text { November 17-21, } \\
2014 \\
\end{array}$ \\
\hline Caraga State University & October 28-30, 2014 \\
\hline
\end{tabular}

Table 1. Schedule of trainings conducted during the project's 1st year of implementation 
Aside from visits to the partner universities, trainings were also held in large groups where all SUCs and HEIs get together in one event. Training on the data processing and field techniques was held on February 16-20, 2015, wherein representatives from the different SUCs and HEIs participated. The training was divided into two venues. The first three days, which were allotted for lectures and exercises on the different methods of processing LiDAR data and high resolution satellite images, was held at the National Engineering Center in University of the Philippines Diliman campus. The two remaining days were allocated for the demonstration of the standard field techniques such as spectral measurement, video tows, gathering of training data sets and use of GNSS receivers. This was conducted at the UP Bolinao Marine Laboratory in Bolinao, Pangasinan. There were a total of 38 participants in attendance.

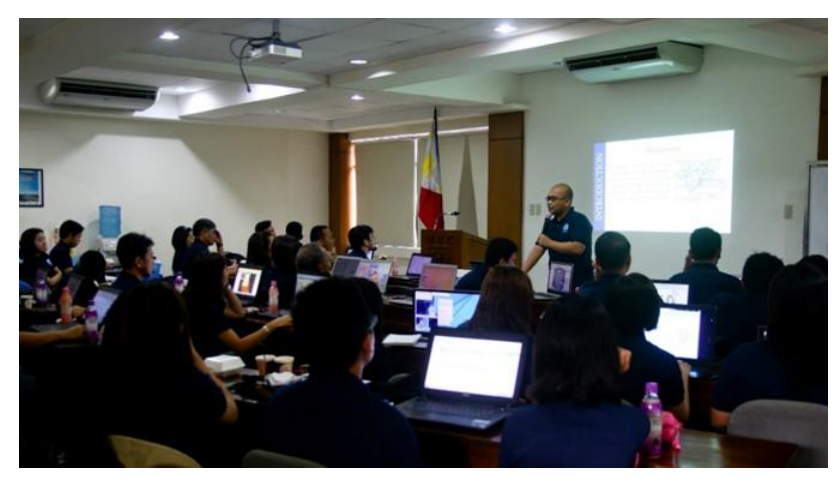

Figure 5. Field Data and Image Processing Lecture at the National Engineering Center, UP Diliman

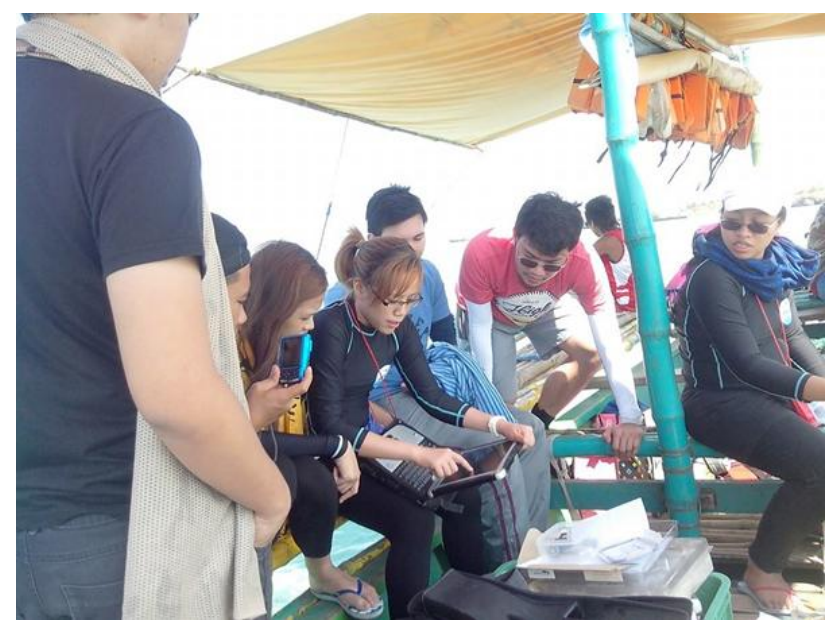

Figure 6. Training on spectral measurement and other field techniques in Bolinao, Pangasinan

A training on the basic Geographic Information Systems (GIS) concepts and methods was also held in the College of Engineering, University of the Philippines Diliman campus on May 18-22, 2015. It aimed to present an introduction on the basic concepts of GIS and how it can be incorporated into the existing classification methods and applied to future analyses. There were 14 SUCs and HEIs that attended the training, with a total of 56 participants.

\subsection{Monitoring of SUCs and HEIs}

After mentoring sessions, monitoring activities are conducted to evaluate each SUC's progress in meeting the project's objectives and targets. Included in the checklist of items for monitoring are: status of equipment procurement (hardware and software), quality and type of available datasets processed, status of field data collection (training and validation datasets), applicability of workplans/targets set and adherence to the standards processing workflow

\begin{tabular}{|c|c|}
\hline $\begin{array}{c}\text { Mariano Marcos State } \\
\text { University }\end{array}$ & $\begin{array}{c}\text { August 10-12, 2015, } \\
\text { February 22-24, 2016 }\end{array}$ \\
\hline Isabela State University & August 10-12, 2015 \\
\hline $\begin{array}{c}\text { Central Luzon State } \\
\text { University }\end{array}$ & $\begin{array}{c}\text { September 7-9, 2015, } \\
\text { March 14-15, 2016 }\end{array}$ \\
\hline $\begin{array}{c}\text { Mapua Institute of } \\
\text { Technology }\end{array}$ & $\begin{array}{c}\text { July 1-3, 2015, February } \\
18-19,2016\end{array}$ \\
\hline UP Los Baños & $\begin{array}{c}\text { August 18-20, 2015, } \\
\text { February 17-19, 2016 }\end{array}$ \\
\hline Ateneo de Naga University & $\begin{array}{c}\text { August 25-27, 2015, } \\
\text { March 14-15, 2016 }\end{array}$ \\
\hline UP Cebu & June 8-11, 2015 \\
\hline University of San Carlos & June15-17, 2015 \\
\hline Visayas State University & June 18-22, 2015 \\
\hline $\begin{array}{c}\text { Ateneo de Zamboanga } \\
\text { University }\end{array}$ & September 20-24, 2015 \\
\hline $\begin{array}{c}\text { Mindanao State University- } \\
\text { IIT }\end{array}$ & October 5-8, 2015 \\
\hline UP Mindanao & September 14-19, 2015 \\
\hline Caraga State University & September 30-October 2, \\
\hline
\end{tabular}

Table 2. Schedule of monitoring sessions

\subsection{Coordination with Concerned Agencies}

One of the objectives of the project is to develop high resolution and high accuracy maps of coastal resources nationwide. In order to attain this goal, included in the project's targets are the coordination with concerned offices and the collection of secondary data. Coordination with concerned government offices is necessary to ensure that jurisdictions of these agencies within the study areas are recognized, such as in the mapping of aquaculture resources or the conduct of field surveys within marine protected areas. The meetings with identified government agencies are also essential in order to discuss data availability and set up collaborations to address data and information gaps.

The project also held trainings for the Bureau of Fisheries and Aquatic Resources (BFAR) on the basics of remote sensing and hands on processing of WorldView-2 data for mapping of coastal resources.

\subsection{Trainings and Conferences}

Trainings are attended by project members to continuously update the project's technical knowledge base. The introduction of new processing methods is essential in the development or refinements in the project's workflows. One of those activities is the Airborne Hyperspectral CASI (Compact Airborne Spectrographic Imager) Imaging Training.

The project also sends representatives to conferences held both locally and abroad to present the project and papers on the different workflows developed. This is to highlight the 
country's progress in terms of science and technology, particularly in the fields of geomatics and remote sensing.

\begin{tabular}{|c|c|}
\hline April 22-24, 2015 & $\begin{array}{c}\text { 12th CoastGIS Symposium, Cape } \\
\text { Town, South Africa }\end{array}$ \\
\hline May 11-15, 2015 & $\begin{array}{c}\text { 36th International Symposium on } \\
\text { Remote Sensing of Environment } \\
\text { (ISRSE), Berlin, Germany }\end{array}$ \\
\hline July 28-31, 2015 & $\begin{array}{c}\text { 13th South East Asian Survey } \\
\text { Congress (SEASC 2015), Singapore }\end{array}$ \\
\hline September 1-3, 2015 & $\begin{array}{c}\text { 2nd National Mangrove Conference, } \\
\text { Iloilo City }\end{array}$ \\
\hline October 19-23, 2015 & $\begin{array}{c}\text { 36th Asian Conference on Remote } \\
\text { Sensing, Philippines }\end{array}$ \\
\hline
\end{tabular}

Table 3. Conferences attended by the UPD CoastMap Team

\section{FUTURE PLANS}

The coordination with agencies and monitoring of partner SUCs and HEIs is constant until the end of the project. Excellent communication between concerned individuals is crucial for the success of the project.

\subsection{Maps Turnover}

The project has already turned over coastal resources maps to the concerned local government units (LGUs) and government institutions. Printed maps along with their corresponding shapefiles were handed over during the map turnover ceremonies. The $1^{\text {st }}$ turnover was held last December 2015 and the target is to deliver coastal resource maps every quarter of the year until the end of the project.

\subsection{WebGIS Development}

The Phil-LiDAR 2 CoastMap is also tasked to collate all the project outputs from the different SUCs and HEIs. To facilitate this activity, a web-based application with GIS capability is being developed that will cater the transfer of processed data between CoastMap UP Diliman and partner SUCs. Not only will the WebGIS serve as a platform for the inventory of output layers, but also as a repository of all other documents such as processing manuals and fieldwork data.

The project has acquired a server-grade machine that will be used as both web and data server. Transfer, storage and retrieval of documents will be done via secured File Transfer Protocol. On the other hand, inventory, uploading, downloading, and publishing of output layers will be handled by a homedeveloped web GIS application based on a fast growing platform called Geonode. Geonode is a python-based web application platform with built-in GIS capability. Being patterned from Django development, Geonode will make use of every existing python libraries necessary in building a secured web application with rich user experience and sensible data flow with integrated GIS functionality.

The machine has already been set-up at the UP TCAGP and ongoing developments on the web GIS application are being done.

\subsection{Vulnerability Assessment}

The outputs of the project, which includes detailed maps of the coastal features, can be used as basis for the nationwide vulnerability assessment of these resources. With this in mind, the project has started the initial research on the Vulnerability
Assessment of coastal resources. It aims to assess the vulnerability of coastal features such as Corals, Seagrass, Mangorves and Aquaculture areas to meteorological, anthropogenic and climate change hazards. Currently, an indicator-based method that can be implemented in a GIS platform is being developed.

\section{ACKNOWLEDGEMENTS}

The authors would like to thank the Department of Science and Technology (DOST) for funding this research and dissemination.

\section{REFERENCES}

Brock, J., et al. 2009, The Emerging Role of Lidar Remote Sensing in Coastal Research and Resource Management. Journal of Coastal Research, Special Issue 53: 1-5.

Samarkoon, L., et. al. 2008, Effective Approach for Capacity Building in GIS and Remote Sensing Technologies in Developing Countries, In: The International Archives of the Photogrammetry, Remote Sensing and Spatial Information Science, Beijing, China, Vol. XXXVII, Part B6a, pp 201-205. 